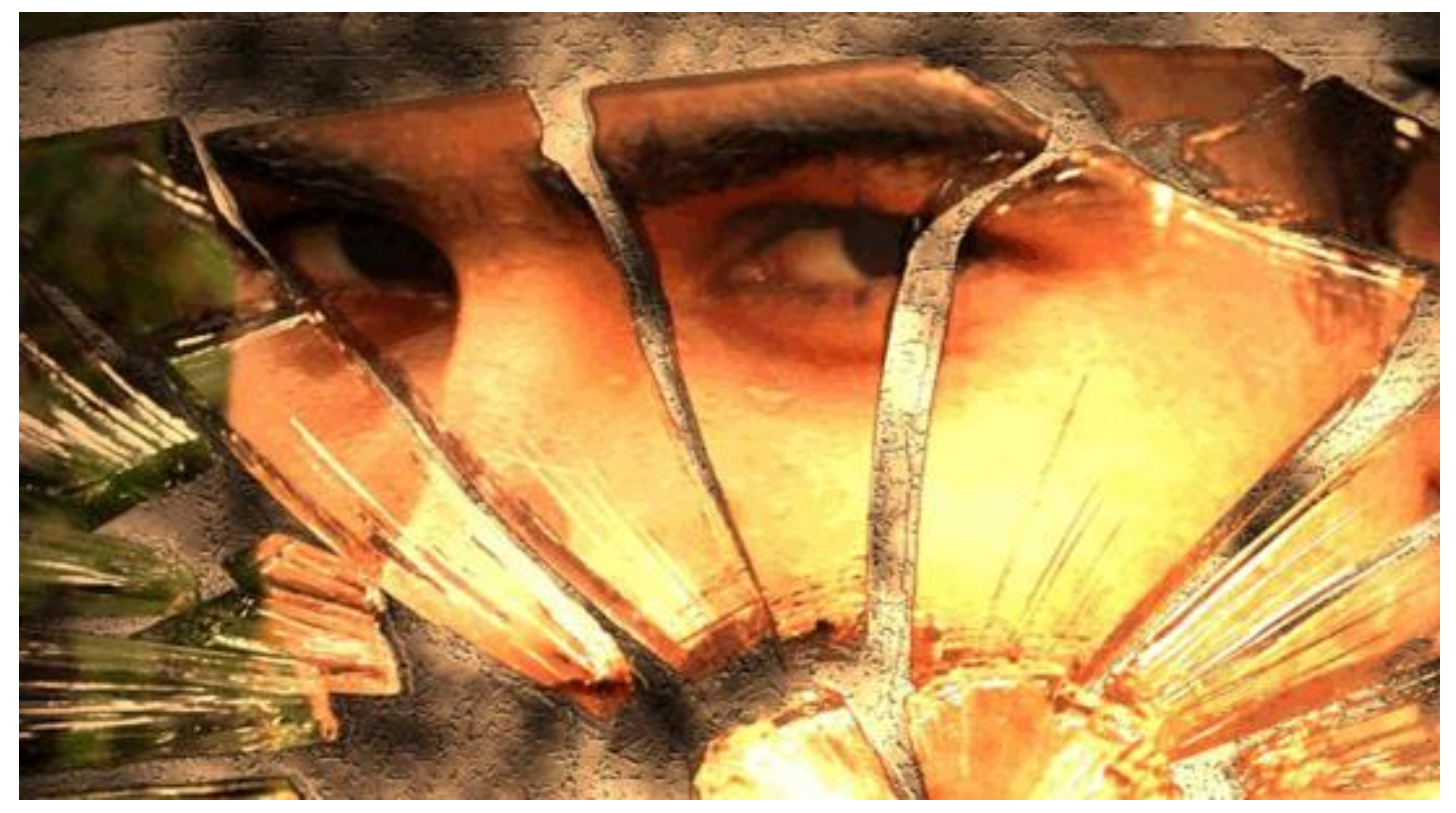

\title{
A contrapelo: incursão teórica na tecnologia - discurso eletrônico, escola, cidade ${ }^{\mathbf{1}}$
} (Against the grain: theoric incursion in the technology - eletronic discourse, school, city)

\section{Eni Puccinelli Orlandi*}

\section{Resumo}

Neste artigo, colocamos em relação o discurso do analista de sistema e o do analista de discurso, procurando mostrar como, pela análise de discurso, se pode compreender o modo de constituição dos sentidos e dos sujeitos - tanto em sua função de autoria como no efeito leitor - quando tomamos como objeto de observação o espaço digital. Para tal, mobilizamos reflexivamente noções como interação, interpretação, navegar, percorrer relações, deriva, distintas noções de memória, fato, dado, textualidade, visando a diferença entre ser usuário e ser sujeito de conhecimento.

Palavras-chave: discurso digital; função autor; efeito leitor; usuário; sujeito.

\begin{abstract}
In this article, we compare the discourse of a systems analyst to that of a discourse analyst, attempting to show by the analysis of the discourse how one can comprehend the mode of constitution of the senses and of the subjects - in both their author function and in their reader effect - when we take digital space as the object of observation. In so doing, we reflectively mobilize notions such as interaction, interpretation, navigation, travel links, drift, distinct notions of memory, facts, data and textuality, seeking the difference between the language user and the language subject.
\end{abstract}

Keywords: digital discourse; author function; reader effect; user; subject.

\footnotetext{
${ }^{1}$ Esse artigo foi escrito no interior do grupo de pesquisa E-urbano, coordenado por Cristiane P. Dias do Labeurb/Unicamp.

${ }^{*}$ Professora no Departamento de Linguística do Instituto de Estudos da Linguagem/Unicamp, Coordenadora do Laboratório de Estudos Urbanos (Labeurb) - Unicamp e Coordenadora do mestrado em Ciências da Linguagem na Univás (MG). Endereço postal: R. Caio Graco Prado, 70. Cidade Universitária. Campinas-SP. Caixa Postal 6166. Telefone: (19) 3521-7900. E-mail: seclabe@unicamp.br
} 


\section{INTERAÇÃO OU PRÁTICA SOCIAL SIMBÓLICA? COMUNIDADE OU CLASSE}

\section{SOCIAL?}

Nossa presente reflexão é apenas uma nota a respeito do uso de interação no discurso dos internautas e cientistas da informação, no exercício do discurso eletrônico ${ }^{3}$, e do que daí decorre. Devo acrescentar que eu mesma nos anos 70/80 do século XX, levada pela "onda" da dialogia e das leituras de Bakhtin, usei a palavra para significar a relação entre posições-sujeito, sobretudo quando trabalhei com leitura e escola. A palavra era de uso corrente, mas o que eu significava já se remetia à noção de discurso e, portanto, a outro sentido. A partir do momento em que tive consciência disso deixei de usar a palavra interação. E guardei rigorosamente a distância teórica que vai da pragmática (interação) e a análise de discurso que pratico e que tem princípios tais como enunciarei em seguida.

A perspectiva na qual me coloco, como tem sido, é a da análise de discurso, na qual se pensa a relação entre a ideologia e a linguagem. Toma-se assim a relação língua/sujeito/história, e introduz-se o objeto discurso como observatório para compreender como a materialidade específica da ideologia é o discurso e a materialidade específica do discurso é a língua. Este objeto, o discurso, por sua vez, inaugura um modo de observar-se a constituição do sujeito e do sentido no confronto do político com o simbólico, quando se pensa essa materialidade.

Sujeito e sentido constituem-se ao mesmo tempo, é o que tenho afirmado em inúmeras ocasiões. Isso quer dizer que o sujeito ao significar, significa-se. Este é um processo complexo. Há a interpelação do indivíduo, afetado pela língua, em sujeito pela

\footnotetext{
${ }^{3}$ Cunhei esta expressão, discurso eletrônico, para significar o discurso da automatização, em reunião com os pesquisadores, no Laboratório de estudos urbanos, para nomear um programa de atividades que estava estruturando no laboratório, em 2002. Em 2003 publicamos "Para uma enciclopédia da cidade", resultado de trabalho da equipe. Na introdução deste livro utilizo igualmente a expressão discurso eletrônico. E o tenho tomado como objeto de análise desde então.
} 
ideologia, o que resulta em uma forma sujeito histórica, em nosso caso, a capitalista. Esta, por sua vez, declina-se em sua relação com o Estado de maneira própria à sua forma. Como o Estado capitalista funciona pelo jurídico, esta forma sujeito funciona com seus direitos e deveres. O Estado, por sua vez, cumpre o seu modo de funcionamento, capitalista, individualizando o sujeito pela prática de suas Instituições e Discursos. E aí temos a forma sujeito individualizada, constituindo-se como um sujeito ao mesmo tempo livre, dono de sua vontade, e responsável. Liberdade e submissão, ser determinador e ser determinado, eis a contradição que o sujeito assume em seu próprio modo de funcionamento na ideologia capitalista.

Como material de análise, procurei tomar como objeto de minha observação fragmentos de discursos de especialistas, isto é, de analistas de sistema. Pois bem, ao ler a proposta feita por Fábio $\operatorname{Bastos}^{4}(03 / 05 / 07)$ em uma primeira reunião de trabalho sobre o e.Urbano, chamou-me logo a atenção o seu primeiro parágrafo sobre o "usuário":

A internet hoje não é mais como era há alguns anos. Até pouco tempo atrás navegávamos na internet e somente recebíamos dados. Atualmente sempre interagimos enviando dados que transformam-se em informações em formato de textos, imagens, sons e vídeos. Navegando na internet muitas vezes nos sentimos no ambiente urbano (grifos nossos).

Pensados através da análise de discurso, haveria um deslizamento (efeito metafórico: PÊCHEUX, 1990) para noções como: usuário = sujeito; navegávamos = percorríamos relações; dados = fatos de linguagem; interagimos = praticamos gestos de interpretação; transformam-se = derivam; informações = sentidos; formato de textos $=$ discursos textualizam-se em diferentes materialidades significantes como textos verbais, imagens, sons, vídeos; ambiente urbano = condições de produção urbanas.

\footnotetext{
${ }^{4}$ Fábio é nosso analista de sistema, no Labeurb, e tem trabalhado conosco em diferentes projetos, ora nos instrumentando com objetos digitalizados, ora procurando refletir conosco sobre o próprio modo de funcionamento do discurso digital.
} 
É justamente sobre estes deslizes - em que temos de um lado, o discurso do analista de sistema, mas também o discurso do senso-comum referido ao digital, e, de outro, o do analista de discurso - e os deslocamentos teóricos e analíticos que vamos falar neste trabalho.

\section{MEMÓRIA DISCURSIVA}

Temos trabalhado com o fato de que há na produção de sentidos três momentos, inseparáveis, que são: constituição, formulação e circulação e sentidos.

Embora inseparáveis, podemos dizer que quando pensamos a prática do discurso eletrônico, tomamos como ângulo de entrada a circulação dos sentidos, pensando os outros dois momentos através deste.

O modo de circulação dos sentidos no discurso eletrônico nos faz pensar que, pela sua especificidade, produz conseqüências sobre a função-autor e o efeito-leitor que ele produz. E estas consequiências estão diretamente ligadas à natureza da memória a que estes sentidos se filiam. E, certamente, à materialidade significante de seus meios ${ }^{5}$.

Trarei, então, para esta reflexão, a distinção que tenho proposto entre: memória discursiva ou interdiscurso, memória institucional (arquivo) e memória metálica (técnica).

A memória discursiva ou interdiscurso (PÊCHEUX, 1975 ; COURTINE, 1982), é a que se constitui pelo esquecimento, na qual "fala uma voz sem nome" (COURTINE,

\footnotetext{
${ }^{5}$ Gostaria de lembrar rapidamente que em meu livro Interpretação (1996) distingo o dispositivo ideológico do dispositivo teórico e do dispositivo analítico da interpretação. $\mathrm{Na}$ construção do dispositivo analítico da interpretação, mostro como é importante: a questão do analista, a natureza significante do material que ele analisa, seus objetivos, e a área disciplinar de que ele parte para sua análise. Portanto, o dispositivo analítico terá sua forma afetada pela natureza do material significante: não se analisa da mesma maneira um texto verbal e uma estátua, ou uma pintura, etc. Isto é a abertura do simbólico e esta abertura deve ser levada em conta pelo analista, respeitando as diferentes materialidades significantes com que trabalha. Assim também com o discurso eletrônico, ou mais geralmente, o digital, em sua materialidade específica.
} 
op.cit). Aquela em que "algo fala antes, em outro lugar, independentemente" (PÊCHEUX, op.cit.), produzindo o efeito do já-dito.

Por outro lado, a memória institucional ou a que chamo a memória de arquivo ou simplesmente o arquivo, é aquela que não esquece, ou seja, a que as Instituições (Escola, Museu, políticas públicas, rituais, eventos etc.) praticam, alimentam, normatizando o processo de significação, sustentando-o em uma textualidade documental, contribuindo na individualização dos sujeitos pelo Estado, através dos discursos disponíveis, à mão, e que mantêm os sujeitos em certa circularidade.

E considero, enfim, a memória metálica, ou seja, a produzida pela mídia, pelas novas tecnologias de linguagem. A memória da máquina, da circulação, que não se produz pela historicidade, mas por um construto técnico (televisão, computador, etc.). Sua particularidade é ser horizontal (e não vertical, como a define Courtine), não havendo assim estratificação em seu processo, mas distribuição em série ${ }^{6}$, na forma de adição, acúmulo: o que foi dito aqui e ali e mais além vai se juntando como se formasse uma rede de filiação e não apenas uma soma, como realmente é, em sua estrutura e funcionamento. Este é um efeito - uma simulação - produzido pela memória metálica, memória técnica. Quantidade e não historicidade. Produtividade na repetição, variedade sem ruptura. E o mito, justamente, desta forma de memória é o "quanto mais, melhor". O que é discutível do ponto de vista do que chamamos memória discursiva, a constituída pelo esquecimento. Por ela, sabemos que o possível está justamente no esquecimento. Dessa perspectiva, é pouco favorável ter-se uma memória saturada.

\footnotetext{
${ }^{6}$ É interessante observar que o usual, quando se fala do digital, é falar-se em redes. No entanto, face à questão da memória, a filiação a redes é fato da memória discursiva, o interdiscurso. Já a memória metálica, técnica, não produz redes em profundidade, mas serialização na/de superfície. Repetição e quantidade, em sua forma binômica.
} 


\section{As diferentes formas de memória acarretam diferenças no circuito} constituição/formulação/circulação e também afetam a função-autor e o efeito-leitor. Isto porque qualquer forma de memória tem uma relação necessária com a interpretação (e, conseqüentemente, com a ideologia.).

\section{INTERAÇÃO?}

Pelo que dissemos acima, a noção de interação fica sujeita a críticas. Se pensarmos que a linguagem não é transparente, que os sujeitos não são a origem de si e que os sentidos são produzidos em processos em que funciona a determinação histórica, podemos resignificar a noção, tão usual no discurso eletrônico, de interação, pela idéia de produção/prática de gestos por sujeitos que ocupam certas posições na relação com este processo de significação. Queremos lembrar que, como diz Pêcheux (1969), gestos são atos no nível simbólico. Quando eu junto gestos a interpretação, desloco o que diz Pêcheux para abarcar mais do que para ele eram os gestos (assobiar, jogar uma bomba numa assembléia, etc.). No modo como tomo a questão do gesto e o ligo a interpretação, estou dizendo que, na prática simbólica, produzimos gestos de interpretação, sendo estes, modos de interferir no mundo, através da prática simbólica que é a interpretação. Repito: a interpretação é uma prática (simbólica) em meio a outras práticas (sociais).

\section{DADOS TRANSFORMAM-SE EM INFORMAÇÕES EM FORMATO DE TEXTOS, DE} IMAGENS, DE VÍDEOS, DE SONS

Como já dissemos mais acima, no discurso não tratamos com dados, mas com fatos de linguagem, de muitas e diversas naturezas. O fato tem materialidade e é pensado em seu processo de constituição. Não é mero produto. Portanto, no enunciado que é o subtítulo 
desta parte, o que afirmamos é que há fatos de linguagem que se transformam em informações. Ora, o modo como se dão na linguagem, dominadas pelo que chamamos efeito metafórico, as transformações, são o que chamamos "deriva”. E a deriva, que é transferência, efeito metafórico, nos restitui ao processo em que a rede de memória, as filiações - e as falhas, o equívoco - fazem efeito. E o efeito aqui é o de termos como resultado "informações". No discurso temos menos informações do que efeitos de sentidos, nos ensina M. Pêcheux (Ibidem). "Informações" que, por sua vez, se seguimos o enunciado do subtítulo, têm o formato de textos, de imagens, de sons, de vídeo. As chamadas "multimídias". Diferentes materialidades significantes com seus diferentes modos de significar.

Formato aí, pensando-se discursivamente, significa a forma do significante. Ou seja, a forma material que é o texto mexe com a natureza da informação, produz efeitos sob o modo como ela funciona. A natureza do significante intervém na produção do objeto e este objeto, por sua vez, constitui o modo de significação deste gesto simbólico.

E o que é um texto? É uma unidade de significação em relação à situação.

Esta sua caracterização pode ser mantida, mas certamente a textualidade, sua forma material, sua relação com a memória e com as condições de produção diferem quando difere sua materialidade significante. Ou seja, podemos considerar uma imagem um texto (ZEN, 2007), mas com sua materialidade diferente ela constitui um objeto simbólico, significante, diverso e que produz efeitos de sentidos específicos a sua forma e sua materialidade. Como tenho dito, há uma abertura do simbólico e as diferentes linguagens, as diferentes materialidades significantes atestam esta abertura pela suas distintas formas de significar, produzindo seus efeitos particulares. 
A questão, então, é: como significam estas diferentes formas materiais no discurso eletrônico? Como o discurso eletrônico arregimenta sentidos a partir da convivência dessas diferentes materialidades significantes, destas diferentes textualidades na produção de seus efeitos (do discurso eletrônico) de sentidos?

Esta é uma abordagem absolutamente inicial, mas se há algo que já posso adiantar é que, da perspectiva discursiva, o que há na relação dessas formas materiais significantes distintas certamente não é simples adição. É uma relação muito mais complexa e que aguarda explicitação. E, habitualmente, o que acontece é que há uma determinação ideológica do verbal sobre o não-verbal, achatando as especificidades. Como se fossem meras adições, soma. No entanto, uma imagem posta junto ao verbal, no digital, não deve ser simples exercício de ilustração, mas significação atestando a abertura o simbólico, dispersão de sentidos.

\section{AMBIÊNCIA E CONDIÇÕES DE PRODUÇÃO}

Podemos pensar o "espaço" face à cidade como parte das condições de produção que constituem a prática significativa da/na cidade. Daí resulta que o espaço urbano, enquanto parte das condições de produção de sentidos, tem suas características e configurações próprias.

Pensamos, assim, que é desse modo, considerando o espaço urbano como parte das condições de produção dos sentidos da/na cidade, que podemos melhor compreender discursivamente o que é “ambiência” (THIBAUD, 2002), em termos simbólico-políticos.

Concebido desse modo, o espaço (urbano) é o enquadramento dos fenômenos ou práticas que acontecem na cidade. Estamos, assim, considerando o espaço como parte do acontecimento discursivo urbano. Portanto, não se trata nem do espaço empírico, nem do 
espaço concreto, material, em si, mas desse espaço material que significa, que tem sua historicidade: espaço de significação, afetado pela interpretação, pela ideologia, em que sujeitos vivem. O que nos leva à distinção de espaço empírico, espaço concreto, material e espaço de significação.

Esta idéia de espaço como enquadramento (HENRY, 1998) que aproximamos, na diferença, da noção de ambiência (THIBAUD, op.cit.), permite-nos trabalhar com a forma e os meios materiais que constituem o espaço urbano como espaço significativo. O que isto quer dizer? Quer dizer que os sentidos são determinados pelas condições de produção, nesse caso, pelo modo como o espaço enquadra o acontecimento urbano. Para nós, enquadrar significa aqui determinar o espaço de significação, em sua materialidade.

Tenho dado alguns exemplos para mostrar o que isto significa. Uma pessoa atravessando a rua experimenta sentidos do espaço urbano que são diferentes de uma pessoa atravessando a cidade em um ônibus. Porque sua experiência do espaço urbano é diferente. São condições de produção diferentes. São diferentes características da ambiência. A maneira como as pessoas se posicionam em uma fila para retirar seu dinheiro no banco ou a maneira como as pessoas se posicionam em uma fila, desde a madrugada, para conseguir uma vaga para seus filhos em uma escola pública, são diferentes porque constituem espaços de significação urbanos diferentes, com diferentes efeitos de sentidos. São dis-posições diferentes do espaço (do sujeito e dos sentidos). Finalmente, um exemplo que costumo dar em aulas: a forma como a escola dispõe a posição dos alunos - sentados em suas carteiras - em relação ao professor - em pé, diante da lousa, ou sentado individualmente na frente da classe - já é uma maneira de significar a relação aluno/professor e de disciplinar o discurso entre eles. Daí se conclui, portanto, que o espaço significa, tem materialidade e não é indiferente em seus distintos modos de significar. 
Quando pensamos o espaço virtual, digital, devemos considerar, já de início, que forma de enquadramento e que fenômenos ele configura.

Ele é fundamentalmente urbano. Mas é necessário refletir sobre o seu modo de inscrição no espaço urbano e o inverso: como o espaço urbano se inscreve nele o qualificando em sua urbanidade.

O fato de pensarmos o urbano digital nos coloca frente à questão: que injunções interpretativas são aí produzidas e que natureza de efeitos isso produz tanto sobre o urbano como sobre o virtual. Como dissemos, o espaço digital - ainda que seja virtual - tem sua materialidade e produz efeitos. Creio que o próximo passo da reflexão, e que deixo em aberto para novas investidas, é o de conhecer o estatuto dessa materialidade e seus efeitos. Tendo esse objeto definido: o virtual urbano que é o que nos interessa. Ou seja, o que da urbanidade afeta o virtual? Pergunta que, como se pode ver, inverte o senso comum que se pergunta em que o virtual afeta o urbano. ${ }^{7}$.

\section{A SUSPENSÃO DA NOÇÃO DE LEITURA NO DISCURSO ELETRÔNICO}

Do mesmo modo que nos anos sessenta (60), a noção de leitura, de interpretação é posta em questão - o que ler significa? - dando espaço a uma reflexão que prepara o lugar de emergência desse novo objeto, o discurso, e da análise de discurso, creio que quando pensamos o discurso eletrônico - noção que assim batizei ao pensar como chamar a reflexão sobre o virtual pensado nos termos da não transparência da linguagem - não podemos deixar de questionar, como um paralelo, o que o enquadramento da linguagem no

\footnotetext{
7 Esta última parte do texto foi extraída e adaptada de "O Espaço Significativo da Violência", texto que apresentei em seminário na UFBA.
} 
discurso eletrônico produz como efeito. E retorna a mesma questão, agora frente a outro artefato: o que ler aí significa?

\section{ESCOLA E DISCURO ELETRÔNICO}

Todas estas questões que coloco aqui têm um objetivo particular que é o de pensar a escola nessa conjuntura discursiva que se instala e nos diferentes processos de leitura que se abrem como possibilidade. Talvez da tomada em consideração da materialidade da leitura no discurso eletrônico possam resultar novos modos de acesso aos sentidos, ao conhecimento. Mas continua, a meu ver, o que já afirmava nos anos 80: ler é saber que o sentido pode ser outro. Só que os percursos para esse outro passam por outros modos de circulação, outras conjunturas da significação.

Por fim, gostaria de retomar aqui uma afirmação que faço no livro Cidade dos Sentidos (2004), ao me referir à escola. Dizia então que, se nos anos 80 do século XX, a grande novidade era dizer que era preciso deixar que a vida lá fora entrasse para a Escola, nos anos 90, a ruptura estava em levar a Escola para a rua. Nessa ocasião, dizia isso pensando as pichações, o rap e outras formas de relação com a linguagem. Pois bem, agora pondo em jogo a relação do urbano com o digital, essas linhas divisórias são mais fluidas e permeáveis. Penso que a Escola ${ }^{8}$ encontra vários meios de ir para a rua e de trazer a rua para dentro. E um deles é, sem dúvida, o digital em seus múltiplos funcionamentos. E podemos citar como exemplo o trabalho que está sendo feito por um conjunto de universidades, o Cidade do Conhecimento, em que se põe em circulação o conhecimento

\footnotetext{
${ }^{8}$ O que tem sido muito discutido já que, muitas vezes, a Escola tem perdido sua especificidade como instituição do Estado articuladora do simbólico com o político. Nesses casos, ela pouco se distingue dos discursos de divulgação deixando de ser lugar de formação, produção de conhecimento e mesmo de administração da memória institucional.
} 
através do Second Life. E não penso que pare aí a possibilidade de se explorarem as novas tecnologias. Mas não posso terminar sem deixar algumas perguntas: que espécie de sujeito e de sentidos estas novas tecnologias produzem? O efeito leitor que resulta dessa relação que se estabelece entre a memória técnica e o conhecimento, em sua forma e funcionamento, pode produzir deslizamento, dependendo de como se trabalha com as condições de produção aí investidas. Se assim é, o que da Escola aí se perde? O que se ganha? Que conhecimento é este que está na rua... circulando pelo espaço digital? Ao responder estas questões podemos, enfim, saber a diferença entre ser um usuário ou um sujeito de conhecimento.

\section{REFERÊNCIAS BIBLIOGRÁFICAS}

COURTINE, J.J. Définition d'orientations théoriques et construction de procedures en analyse de discourse. Philosophiques. Paris: 2, vol.IX, 1982.

HENRY, P. Texto enviado por email sem título, sobre espaço. 1998.

ORLANDI, E. (org). Para uma Enciclopédia da Cidade. Campinas: Pontes, 2003. . Cidade dos Sentidos. Campinas: Pontes, 2004. - Interpretação - autoria, leitura e efeitos do trabalho simbólico.

Petrópolis: Vozes, 1996.

PÊCHEUX, M. Analyse Automatique du Discours. Paris: Dunod, 1969. . Les Vérités de la Palice. Paris: Maspero, 1975.

THIBAUD, J-P. L’horizon des ambiances urbaines. In Communications. Paris: 73, Seuil, 2002. 
ZEN, Tânia. A construção do sujeito-leitor na crônica fotográfica. 2007. 136p. Tese

(doutorado em Lingüística), Instituto de Estudos da Linguagem, Universidade Estadual de Campinas, Campinas, 2007. 
Revista do Laboratório de

Estudos Urbanos do Núcleo

\section{Para citar essa obra:}

ORLANDI, Eni Puccinelli. A contrapelo: incursão teórica na tecnologia: discurso eletrônico, escola, cidade. RUA [online]. 2010, no. 16. Volume 2 - ISSN 1413-2109

Consultada no Portal Labeurb - Revista do Laboratório de Estudos Urbanos do Núcleo de

Desenvolvimento da Criatividade

http://www.labeurb.unicamp.br/rua/

\section{Laboratório de Estudos Urbanos - LABEURB \\ Núcleo de Desenvolvimento da Criatividade - NUDECRI}

Universidade Estadual de Campinas - UNICAMP

http://www.labeurb.unicamp.br/

\section{Endereço:}

Rua Caio Graco Prado, 70

Cidade Universitária "Zeferino Vaz" - Barão Geraldo

13083-892 - Campinas-SP - Brasil

Telefone/Fax: (+55 19) 3521-7900

Contato: http://www.labeurb.unicamp.br/contato 